\title{
PARTICIPAÇÃO DISCENTE NAS PUBLICAÇÕES DA PÓS-GRADUAÇÃO: UM ESTUDO COMPARATIVO ENTRE PROGRAMAS PÚBLICOS E PRIVADOS DE ADMINISTRAÇÃO
}

\author{
Saulo Aparecido Souza* \\ JOSÉ NILSON REINERT**
}

Recebido: 24 set. 2011

Aprovado: 19 dez. 2011

\begin{abstract}
* Mestre em Administração pela Universidade Federal de Mato Grosso do Sul. Atua principalmente no tema Pesquisa no Ensino da Administração. Campo Grande, MS. E-mail: souza.saulo@hotmail.com

** Dr. em Administração de Empresas pela EAESP/FGV e Pós-doutorado na New School for Social Research, USA. É professor da Universidade Federal de Mato Grosso do Sul. Campo Grande, MS. E-mail: icaro.phenix@uol.com.br
\end{abstract}

Resumo: Este estudo analisa a participação discente nas publicações de programas públicos e privados de pós-graduação em Administração brasileiros entre 2000 e 2008, bem como possíveis diferenças nas participações por tipo de publicação. Realizou-se um levantamento incluindo 2.995 publicações de 38 programas de pós-graduação em Administração, no intervalo entre 2000 e 2008, a partir de dados secundários da Coordenação de Aperfeiçoamento de Pessoal de Nível Superior (Capes). Os resultados indicam que a participação discente nas publicações dos programas de pós-graduação em Administração é maior entre os programas de instituições de ensino superior (IES) públicas do que nas privadas ao longo da série. Já a participação em relação ao total publicado pelos respectivos segmentos é maior entre os programas de IES públicas no início do intervalo 2000-2008, mas se tornou não significativamente diferente nos últimos anos da série. A participação discente nas publicações dos programas de IES privadas está aumentando em uma razão maior do que a verificada em programas de IES públicas.

Palavras-chave: Publicação discente. Publicação na pós-graduação. Avaliação da pós-graduação.

\section{STUDENT PARTICIPATION IN THE PUBLICATIONS OF GRADUATE SCHOOLS: A COMPARA- TIVE STUDY BETWEEN PUBLIC AND PRIVATE ADMINISTRATION PROGRAMS}

Abstract: This study analyses the student participation in publications of Administration graduate programs, in Brazil, between public and private programs, as well as possible differences in participation by type of publication. A survey was conducted to collect data of 2,995 publications from 38 Administration graduate programs, corresponding to the period between 2000 and 2008, based on secondary data of Coordenação de Aperfeiçoamento de Pessoal de Nível Superior (Capes). Results indicate that student participation in the publications is higher in public programs than in private ones throughout the series. The participation in relation to each segment was higher among the programs of public institutions at the beginning of the interval 2000-2008, but became not significantly different in the last years of the series. Student participation in publications of the private segment is increasing at a rate greater than that seen in the programs of public institutions.

Key words: Student publication. Graduate student publication. Graduate evaluation. 


\section{INTRODUÇÃO}

O Brasil vem apresentando um crescimento expressivo de sua produção científica. Em parte, esse crescimento acompanha o desenvolvimento da pósgraduação, que se deu com maior força a partir da década de 1970. Mas é a partir do início da década de 1990, principalmente, que o país vivencia um verdadeiro "boom" na quantidade de publicações, sobretudo em periódicos indexados. Nesse ponto, cumpre notar que é nas instituições de ensino superior (IES) que a maior parte dessa pesquisa se processa. Mesmo nos países mais desenvolvidos, que destinam grandes montantes de recursos públicos e privados para pesquisa, são as universidades que concentram a maior parcela de pesquisadores de alto nível e é nelas que são desenvolvidas as pesquisas básicas (SCHWARTZMAN; CASTRO, 1986).

Nos últimos anos, verifica-se uma discrepância no crescimento das quantidades de programas em IES privadas, em relação ao crescimento de programas em IES públicas. Segundo dados da Coordenação de Aperfeiçoamento de Pessoal de Nível Superior (CAPES, 2010a), nas privadas, a quantidade de programas de pós-graduação em Administração cresceu 567\% entre 1998 e 2008, ao passo que, nas públicas, cresceu $158 \%$. A quantidade de discentes titulados acompanhou essa diferença, de modo que, nas privadas, cresceu quase $600 \%$, enquanto que nas públicas cresceu $168 \%$. Ocorreu, portanto, um crescimento tanto de programas quanto de titulados mais acentuado entre programas de IES privadas do que em programas de IES públicas.

Outro fenômeno, conferido na pós-graduação brasileira, é uma discrepância no crescimento das quantidades relativas de estudantes e de docentes nos programas de pós-graduação. Segundo dados da Capes (2010a), entre 1998 e 2008, houve um crescimento de $99 \%$ na quantidade de docentes nos programas de pós-graduação brasileiros. Já a quantidade de discentes aumentou 187\%. Talvez uma consequência desse aumento na proporção de estudantes em relação ao corpo docente seja o crescimento conferido nas publicações discentes. De acordo com levantamento realizado pelo Ministério da Ciência e Tecnologia (BRASIL, 2009), com base em dados dos Diretórios de Grupos de Pesquisa do Conselho Nacional de Desenvolvimento Científico e Tecnológico (DGP/ CNPq), a quantidade de estudantes autores cresceu quase 50\% entre 2000 e 2008. Porém, no mesmo período, a quantidade de pesquisadores autores (não estudantes) cresceu apenas $20 \%$.

Portanto, ocorreu um crescimento relativo acentuado da participação dos programas de IES privadas em relação aos programas de IES públicas e, ao mesmo tempo, um crescimento também acentuado da quantidade de estudantes 
em relação à quantidade de docentes. Vale ressaltar que a pesquisa faz parte da formação de estudantes de pós-graduação stricto sensu. Seja a publicação um princípio educativo e formativo (DEMO, 1991, 1998), seja por ser a atividade percebida pelos estudantes de pós-graduação em Administração como a mais importante na formação de competências (NOGUEIRA, 2007), seja como condição exigida pelos regulamentos dos cursos de pós-graduação para a obtenção do título, seja por outras razões, o fato é que os discentes produzem trabalhos científicos ao longo do curso e, em muitos casos, estes mesmos trabalhos acabam sendo publicados.

Essas observações abrem espaço para se questionar em que medida os estudantes participam das publicações em programas de pós-graduação em Administração com diferentes status jurídicos (públicos e privados). A expansão recente dos programas das IES privadas, mais particularmente entre 2000 e 2008, talvez tenha influenciado na participação das publicações com autoria dos estudantes pertencentes aos programas das mesmas no total de publicações dos Programas de Pós-Graduação em Administração. Os estudos que investigam a participação discente nas pesquisas dos programas são escassos, talvez por ser um fenômeno ainda recente.

Desse modo, esse estudo tem como objetivo analisar o grau de participação discente nas publicações dos programas de pós-graduação em Administração brasileiros entre programas com diferentes status jurídicos. Especificamente, procura identificar a participação discente entre programas de IES públicas e privadas, entre 2000 e 2008, bem como possíveis diferenças nas participações por tipo de publicação.

\section{PUBLICAÇÃO DISCENTE NA PÓS-GRADUAÇÃO}

Muitos dos pressupostos da universidade moderna têm sua origem na organização da universidade alemã do século XIX. Três princípios fundamentais da universidade moderna são oriundos desse modelo: unidade entre ensino e pesquisa, liberdade acadêmica e centralidade da Faculdade de Filosofia (KWIEK, 2008). Esse modelo fundamentou a criação de universidades de pesquisa em vários países, como no Canadá (FALLIS, 2004), nos Estados Unidos (VERHINE, 2008) e no Brasil, como, por exemplo, no caso da Universidade de São Paulo (PAULA, 2002, 2009). Mas, o elemento que ocupou posição central na ideia de universidade alemã foi a integração entre ensino e pesquisa (BAHRO; BECKER, 1979), bastante adequada ao âmbito da pós-graduação (DEMO, 1998). 
O processo de educação pela pesquisa resulta, geralmente, em trabalhos científicos. Essas pesquisas representam uma parte importante da produção intelectual da universidade, especialmente no caso do doutorado, onde se exige alguma contribuição original à área de conhecimento. Algumas modalidades, inclusive, são intensivas em pesquisa, como o Ph.D por publicação, que se baseia em uma série de artigos publicados ou aceitos para publicação (PARK, 2007). A publicação pode começar por modos preliminares e internos, mas as oportunidades crescem com o tempo e com o aumento da excelência (DEMO, 1998).

Na pós-graduação, o estudante precisa assumir papel ativo e participativo. Idealmente, não basta ser um aluno-objeto, que apenas escuta aula e a reproduz na prova, mas um aluno-sujeito, que trabalha com o professor, reconstrói conhecimento e participa ativamente em tudo (DEMO, 1998). Assim, como afirma Humboldt: "[...] the teacher does not exist for the sake of the student: both teacher and student have their justification in the common pursuit of knowledge" (HUMBOLDT apud CLARK, 1997, p. 244).

Como benefício para o próprio estudante, a publicação discente pode estimular a manutenção de uma abordagem crítica e propiciar melhoras no currículo acadêmico (TIMMONS; PARK, 2008). Publicar também ajuda a desenvolver um perfil de maior credibilidade acadêmica, maiores oportunidades de carreira, maior desenvolvimento erudito e profissional e, ainda, facilita o recebimento de financiamentos, pois muitas agências dão preferência a resultados tangíveis no curto prazo (ROBINS; KANOWSKI, 2008). Um estudo em um programa de pós-graduação em Administração brasileiro indica que a participação em pesquisas é a atividade do curso que mais contribui para o desenvolvimento de competências, na opinião dos estudantes (NOGUEIRA, 2007).

Por parte dos programas, pode ocorrer estímulo para que sejam elaborados manuscritos empíricos ou conceituais, revisões de literatura estruturadas ou position papers (NOLAN; ROCCO, 2009). Em outros casos, artigos são componentes da avaliação do estudante ou estes são alertados sobre a possibilidade de publicação logo no início do curso e encorajados acerca dessa possibilidade durante o mesmo (TIMMONS; PARK, 2008).

Diversos programas de pós-graduação brasileiros estimulam a publicação discente. É prática comum a exigência de submissão ou publicação de artigos científicos, por parte do estudante, como requisito para a obtenção do título, previsto nos regulamentos dos programas. Em geral, exige-se a produção de um a dois artigos ao longo do curso. Há casos, ainda, onde se especificam níveis mínimos de qualidade dos congressos ou periódicos para os quais devem ser submetidos. 
Maccari, Lima e Riccio (2009) apontam evidências de que os coordenadores de programas de pós-graduação em Administração estimulam os professores a produzir e publicar. Além destes, os estudantes também são encorajados a produzir. Para os coordenadores, quando os estudantes produzem, o programa está sendo mais eficaz. Os programas investigados pelos referidos autores se utilizam de mecanismos para estimular a produção discente, como incentivos financeiros, validação de créditos ou exigindo-lhes regimentalmente produtos científicos.

\section{DESENVOLVIMENTO DA PÓS-GRADUAÇÃO E EXPANSÃO DAS IES PRIVADAS}

De acordo com a comissão elaboradora do V Plano Nacional de Pós-Graduação (BRASIL, 2004), as atividades de pesquisa científica, tecnológica e de inovação são componentes essenciais para projetar uma nação mais autônoma e capaz de agregar valor a produtos e processos, possibilitando uma inserção competitiva no mercado mundial. Ciência e tecnologia constituem uma "questão de poder” (p. 49), capaz de dividir o mundo entre países produtores de conhecimentos e tecnologias, de um lado, e países que apenas copiam tecnologias estrangeiras, de outro. A pós-graduação brasileira, portanto, constituiria a base para a formação dos recursos humanos necessários ao desenvolvimento científico e tecnológico do país. Foi com base nesse ideario que o Sistema Nacional de Pós-Graduação (SNPG) se desenvolveu.

Segundo Schwartzman (2001), no início da década de 1970, pela primeira vez na história do país, procurou-se colocar ciência e tecnologia a serviço do desenvolvimento econômico. Junto ao fortalecimento e crescimento do setor público, houve um crescimento dos investimentos em projetos de longo prazo, o que incluiu a pós-graduação. Os dois primeiros PNPGs (BRASIL, 1975, 1982) enfatizaram a consolidação do SNPG como uma atividade regular nas universidades, sua expansão e qualidade dos cursos de pós-graduação. Mas, a partir do III PNPG (1986-1989), passou-se a reconhecer a importância de uma maior cooperação técnica e científica entre o setor produtivo e a pós-graduação (BRASIL, 1986).

Segundo Dias Sobrinho (2002), a década de 1980 também marcou o início de um período onde a racionalidade neoliberal dominou o cenário mundial. Houve cortes em investimentos nas áreas sociais, incluindo educação. A justificativa era que as universidades eram incompetentes, dispendiosas e desligadas das necessidades da indústria. Formou-se um 
consenso de que ela era responsável pelo insucesso econômico e pela frágil competitividade internacional de um país. As universidades deveriam ser mais úteis à indústria, rigorosas quanto à qualidade e mais produtivas, com seus recursos reduzidos.

Analisando os três primeiros PNPGs e as transformações da pós-graduação brasileira, Hostins (2006) atribuiu aos acontecimentos históricos das décadas de 1980 e 1990 a alteração da identidade da universidade brasileira: ela transformou seu status de identidade pública, compatível com o Estado de Bem-Estar, para o de identidade mercantil, próprio do Estado empresarial. Para a autora, nesse período, entre outras mudanças, ocorreu forte expansão das matrículas, diferenciação de docentes em função de sua produtividade, internacionalização do conhecimento, diversificação das fontes de financiamento e propostas de mestrados profissionalizantes. Além disso, nesse período, o Estado consolidouse como regulador, determinando a relevância dos processos avaliativos nas políticas educacionais.

Entre 1995 e 2002, Sguissardi (2006) aponta, entre outras transformações da educação superior, a criação de condições para a expansão de instituições de ensino superior privadas com ou sem fins lucrativos. O resultado disso foi um aprofundamento da predominância de IES privadas em relação às públicas. Segundo o autor, o Brasil é o país com o maior índice de privatização do ensino superior na América Latina e um dos cinco primeiros no mundo (considerando o número de IES e o percentual de matrículas).

De acordo com dados do GeoCapes (CAPES, 2010a) havia, em 1998, 1.259 programas de pós-graduação no Brasil. Destes, 9\% eram privados, enquanto que $91 \%$ eram públicos. Em 2008, havia 2.568 programas, sendo 20\% privados e 80\% públicos. Ou seja, entre 1998 e 2008, os programas de IES privadas dobraram sua participação no total de programas brasileiros. A próxima seção apresenta alguns números da pós-graduação em Administração brasileira.

\section{EXPANSÃO DA PÓS-GRADUAÇÃO EM ADMINISTRAÇÃO}

Conforme dados do GeoCapes (CAPES, 2010a), em 2008, havia 71 programas de pós-graduação em Administração, sendo a maioria ofertante apenas de mestrado acadêmico (42\%). Uma crescente quantidade de programas também passou a oferecer cursos de doutorado, além do mestrado acadêmico neste período. Entre 1998 e 2008, os programas que ofereciam apenas mestrado acadêmico cresceram $200 \%$. Por outro lado, os que ofereciam mestrado acadêmico e doutorado cresceram $340 \%$. 
Ao se considerar os cursos individualmente, nota-se um crescimento de 188\% nos mestrados acadêmicos (de 18 para 52), 175\% nos doutorados (de 8 para 22 ) e de $533 \%$ nos mestrados profissionais (de 3 para 19). É importante ressaltar que, quando se diferenciam programas de IES públicas e de IES privadas, ocorre um crescimento relativamente maior de programas nas segundas. Em 1998, 67\% dos programas de pós-graduação em Administração estavam em IES públicas, mas, em 2008, a maior parte estava nas privadas (56\%).

Quanto aos estudantes matriculados, ocorreu um aumento de $111 \%$, passando de 2.101, em 1998, para 4.441, em 2008. Chama atenção o surgimento de uma nova categoria de mestres, os profissionais, que começaram a aparecer na série histórica a partir do ano 1999. Quanto à diferenciação entre público e privado, a contribuição maior para o crescimento total de matriculados foi devida aos programas de IES privadas, pois aumentaram 169\%, diante de 65\% no âmbito público.

Com relação ao corpo discente titulado, também houve crescimento acentuado. A quantidade total de titulados mais que triplicou no período 1998-2008 (aumentou 322\%), sendo parte significativa atribuível aos mestres. Dentre estes, os profissionais aumentaram em torno de $1.400 \%$, passando a representar em torno de $30 \%$ a $40 \%$ do total de mestres titulados a partir de 2003, mesmo tendo começado a aparecer na série histórica apenas a partir de 1999. O número de mestres acadêmicos titulados aumentou $200 \%$ e o de doutores $181 \%$. Novamente, fazendo-se diferenciação entre público e privado, verifica-se um aumento de quase $600 \%$ no âmbito privado diante de $322 \%$ no público.

Por fim, quanto aos docentes, sua quantidade total também cresceu, mas em ritmo menos acelerado do que a quantidade de programas e de discentes titulados. Entre 1998 e 2008, a quantidade de titulados aumentou 322\%, mas a de docentes apenas 192\%. Portanto, considerando-se o intervalo 1998-2008, percebe-se que os programas da área de Administração seguem uma tendência desproporcional de expansão, onde o crescimento de titulados é maior do que o de docentes. Entretanto, o intervalo delimitado para esta pesquisa é apenas entre 2000 e 2008. Nele, a diferença de crescimento nas quantidades de docentes e discentes é um tanto diferente: o crescimento da quantidade de matriculados é igual a $65,33 \%$, de titulados, $95,47 \%$ e, de docentes, $146,38 \%$.

\section{METODOLOGIA}

Utilizando-se da classificação de tipos de pesquisa de Collis e Hussey (2005), esse estudo pode ser considerado um levantamento descritivo, quan- 
titativo e com natureza aplicada. É descritivo, pois, além de serem descritas características dos programas de pós-graduação por meio de estimativas de proporções da população, também foram investigadas possíveis associações entre variáveis. Quanto ao processo, é predominantemente quantitativo, visto que a descrição foi pautada por mensurações de variáveis dos programas, o que envolveu o uso de indicadores quantitativos.

Para Malhotra (2006), as pesquisas descritivas podem ser subdivididas em transversais e longitudinais. Este estudo é um levantamento longitudinal, compreendendo o período entre 2000 e 2008, apesar das limitações verificadas em se estudar os mesmos programas ao longo do tempo. Nesse intervalo, surgiram alguns programas, enquanto que outros deixaram de existir. Definiu-se esse recorte temporal por ser um período mais recente, havendo disponibilidade de dados pela Capes.

A população inicial para a pesquisa foi composta pelas publicações de todos os programas brasileiros de pós-graduação stricto sensu da área de avaliação da Capes denominada Administração, Ciências Contábeis e Turismo, entre 2000 e 2008. Havia um total de 96 programas nessa condição em 2008. Alguns foram excluídos desse total, de acordo com quatro critérios: a) programas cuja Área de Conhecimento informada pela Capes era Ciências Contábeis ou Turismo; b) programas que ofereciam mestrados profissionais; c) programas com menos de três anos de funcionamento, em 2008 (como boa parte da publicação discente é oriunda de trabalhos finais de curso, convencionou-se que o programa deveria ter completado, ao menos, o ciclo de formação da primeira turma ingressante, no caso dos mestrados. Isso ajudou a reduzir a possibilidade de serem tomados cursos cujos corpos discentes estivessem ainda em condições pouco propícias para publicação); e d) programas que não disponibilizavam dados referentes às suas publicações enquanto a pesquisa foi realizada. Restaram, após esta etapa, os 38 programas participantes do levantamento.

Os dados foram coletados a partir dos Cadernos de Indicadores disponibilizados no portal da Capes na internet. Esses Cadernos contêm informações prestadas anualmente pelos programas à Capes por meio de um processo denominado Coleta Capes. Tais informações foram utilizadas durante os processos de avaliação trienais. Para este estudo, foram tomados apenas os Cadernos de Produção Bibliográfica dos programas selecionados, no período delimitado (2000-2008). Tratou-se, portanto, de uma coleta de dados secundários.

Foi realizado um levantamento das quantidades de publicações de cada programa em cada ano do intervalo 2000-2008. Ao todo, os 38 programas 
produziram 29.874 publicações entre artigos em periódicos, artigos em anais de eventos e livros (capítulos, organizações e obras integrais). A partir desse levantamento, também foi possível definir as proporções de cada tipo de publicação, por ano, em relação ao total publicado.

Em seguida, foram estabelecidas amostras de publicações para cada programa, em cada ano, correspondentes a $10 \%$ do total de cada tipo de publicação dos programas. Foram gerados números aleatórios correspondentes às quantidades necessárias de observações para atender a cada segmento da amostra com o auxílio da função ALEATÓRIOENTRE do software Microsoft Excel. Os números aleatórios gerados corresponderam às ordens das publicações tomadas nas listas de publicações contidas nos Cadernos. Quando alguns dos números retornados foram iguais, o processo foi repetido.

Portanto, a amostra desse estudo compreendeu $10 \%$ do total publicado no período, sendo a estratificação estabelecida por ano, programa e tipo de publicação. Como as proporções da população foram respeitadas, tratou-se de uma amostra estratificada proporcional (COOPER; SCHINDLER, 2003; MALHOTRA, 2006). Efetivamente, foram coletados dados de 2.995 publicações.

Dentre os dados disponibilizados nos Cadernos, não fizeram parte da amostra: a) resumos, tendo sido considerados apenas os trabalhos completos; b) artigos da seção "Jornais e Revistas", por serem não-científicos; e c) trabalhos da seção "Outros", pois incluem publicações também não-científicas ou estudos ainda em realização, como resenhas, matérias em sites, textos para discussão, boletins informativos, working papers, etc.

Para a análise dos dados, foi utilizado o indicador bibliométrico contagem de publicações (GLÄNZEL, 2003; OKUBO, 1997; RUEDA-CLAUSEN; VILLA-ROEL; RUEDA-CLAUSEN, 2005). No caso, foi empregada a contagem de publicações relativa ao total de publicações dos programas. A contagem de publicações é uma medida de produtividade relativamente simples. Também é o indicador mais empregado em estudos bibliométricos (MARTIN, 1996). Os testes de hipóteses envolvendo proporções foram realizados conforme Hoffmann (1991). Ao nível de confiança de $95 \%$ e empregando-se como proporção $p=0,5$, foi possível atingir o nível de precisão de aproximadamente $1,7 \%$.

Foi empregado o esquema de contagem completa (whole counting) de cada autor (GLÄNZEL, 2003). Isso significa que cada publicação não foi subdividida em frações para se identificar o quanto de cada trabalho coube a cada autor, mas a cada co-autor de um trabalho foi contada uma publicação. Portanto, caso houvesse algum discente dentre os autores de uma publicação, esta foi contabilizada como sendo uma publicação com autoria discente. 
Para simplificar a análise, foram utilizadas as seguintes definições para as autorias, baseadas em Capes (2010b): a) discente: inclui estudantes matriculados em programas de pós-graduação autores ou co-autores de alguma publicação (graduandos, mestrandos, doutorandos e egressos); b) docente: inclui professores pesquisadores vinculados aos programas de pós-graduação autores ou co-autores de alguma publicação; e c) outro pesquisador: autores que não possuem vínculo com o programa e participam como co-autores em publicações junto a algum autor vinculado ao programa (participantes externos).

\section{RESULTADOS E ANÁLISE DOS DADOS}

Os dados foram coletados de todos os programas participantes. No entanto, em dois casos não foram identificadas publicações com autoria discente na amostra. Alguns programas são recentes e publicaram quantidades relativamente pequenas, no período considerado, quando comparados com programas mais consolidados. Isso, somado à amostragem proporcional, talvez tenha contribuído para que alguns programas tenham sido pouco contemplados na amostragem enquanto que outros não tiveram dados de publicações com autoria discente incorporados aos dados analisados na pesquisa.

Os resultados estão divididos em duas partes. A primeira apresenta a participação discente entre programas de IES públicas e privadas e a segunda faz distinção entre os tipos de publicações (anais, periódicos e livros).

\subsection{Participação discente nas publicações em programas de IES públicas e privadas}

Foram coletados dados de 2.995 publicações. As quantidades tomadas ao longo do período variaram conforme o total nacional de publicações da área de Administração. A Figura 1 apresenta as participações dos discentes de programas de IES públicas e privadas em relação às quantidades totais de publicações amostradas em cada ano. Esses percentuais consideram todos os trabalhos com autoria ou co-autoria discente (anais, periódicos e livros, estes últimos podendo ser obras integrais, capítulos ou organizações/coletâneas). O critério aplicado é amplo, bastando algum dos autores da publicação ser identificado como um estudante. Esse grupo engloba tanto trabalhos produzidos pelos estudantes individualmente quanto elaborados em co-autoria com docentes e outros pesquisadores (participantes externos). Apesar da irregularidade ao longo do intervalo, as proporções têm tendência ascendente. 
Em média, a participação das publicações dos programas de IES privadas com alguma autoria discente no período é igual a 17\%. Isso significa que, do total de publicações da área de Administração, 17\% são oriundas de programas de IES privadas e têm autoria de algum discente (com precisão de 1,7\%). Mas esse valor corresponde a algo em torno da metade do valor atribuível aos programas de IES públicas, que em média, é igual a 39\% (também com precisão de $1,7 \%)$. No entanto, a partir das linhas de tendência e equações das retas, nota-se que a participação das IES privadas cresce em uma razão maior do que a conferida entre as públicas.

Figura 1- Comparativo das participações das publicações discentes dos programas de IES públicas e privadas em relação ao total nacional.

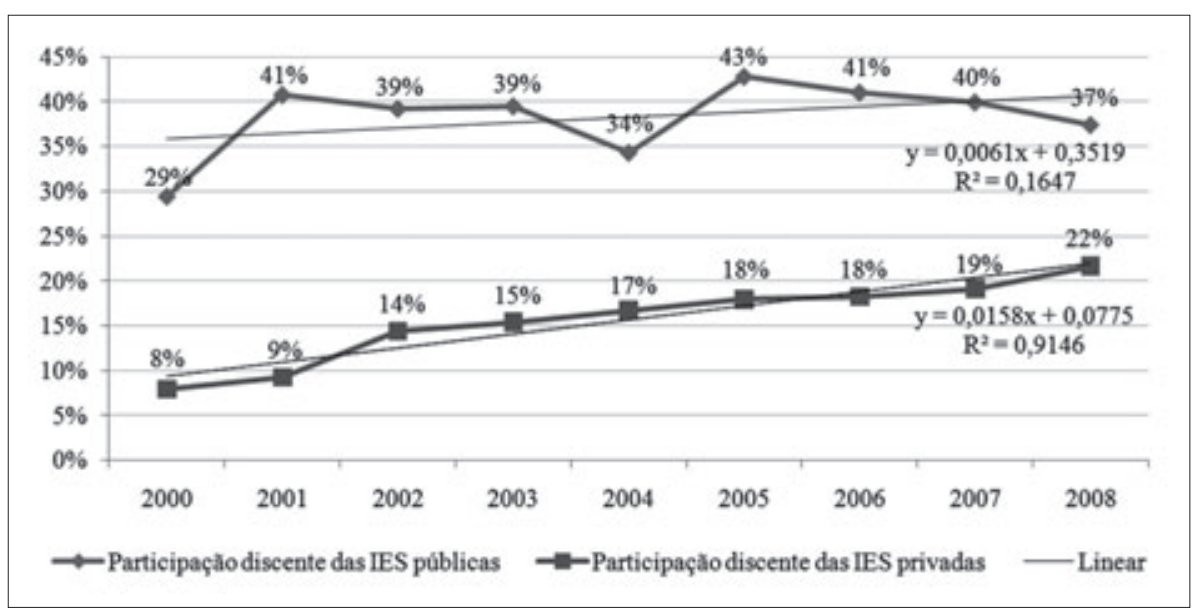

Fonte: elaborado pelos autores.

Essa forma de observar a participação se dá a partir de um denominador comum a ambos os segmentos: as quantidades totais de publicações em cada ano. Porém, a quantidade de publicações provenientes de programas privados representa apenas $34 \%$ da amostra, ao passo que a quantidade de publicações dos programas públicos corresponde a $66 \%$. Isso torna a participação discente nos programas privados, quando verificada em relação ao total de publicações, menor do que a participação nos programas públicos.

Outra forma de interpretar diferenças na participação entre IES públicas e privadas seria considerar a participação em cada um dos segmentos tomando 
como denominadores as diferentes quantidades de publicações dos âmbitos público e privado. A Figura 2 compara as participações, mas, ao invés de tomar uma base comum, indicando a participação em relação ao todo, representa as participações das publicações com autoria discente em cada segmento (computado em relação ao total de publicações de cada segmento - público e privado).

Nessa perspectiva, a participação média no segmento privado, considerando todo o período, é de $50 \%$. No âmbito público, é de $59 \%$. Contudo, como a taxa de crescimento da participação discente nas publicações é maior entre as IES privadas, no último ano da série (2008), a participação destas (60\%) ultrapassa a participação nas IES públicas (59\%). A participação média é significativamente maior entre as IES públicas durante o período 2000-2008 ( $<<0,001$ ). Também é moderadamente maior nos anos 2001, 2002 e 2003 (p < 0,05) e muito maior nos anos 2003 e 2005 ( $\mathrm{p}<0,001)$. Nos demais anos, não há diferença significativa, inclusive nos dois últimos da série (para os anos 2000, 2004, 2007 e 2008 os p-valores são, respectivamente: 0,187; 0,170; 0,555; e 0,749).

\section{Figura 2- Comparativo das participações das publicações discentes nos programas de IES públicas e privadas em relação aos totais de cada segmento.}

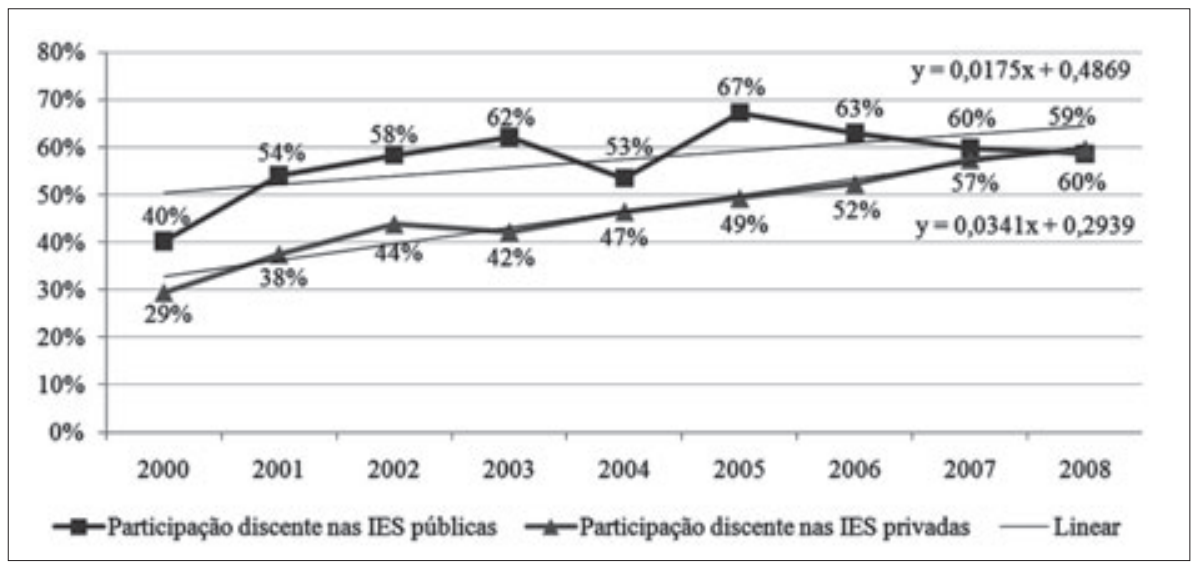

Fonte: elaborado pelos autores.

Ocorrem tendências de crescimento muito semelhantes entre a participação discente nas publicações das IES privadas em relação ao total de publicações, a participação dos discentes matriculados em IES privadas em relação ao total de matriculados e a participação dos programas de IES privadas no total de 
programas de pós-graduação em Administração brasileiros. A Figura 3 reúne essas participações, sendo possível se obter uma aproximação das taxas de crescimento a partir das equações das retas.

Apesar das variações anuais, é possível notar tendências similares entre as retas. Isso pode ser interpretado dentro do contexto de expansão da participação das IES privadas no sistema nacional de pós-graduação em Administração como um todo: está aumentando sua quantidade relativa de programas e de estudantes no período em análise.

Segundo dados da Capes (2010a), do total de programas, no ano 2000 (excluindo-se os classificados nas áreas Ciências Contábeis e Turismo), 9 eram privados, o que representava 37\% do total. Em 2008, já eram 40, passando a representar 56\% do total. Com relação à quantidade de estudantes matriculados, em 2000, representavam 41\%, passando a 57\% em 2008. Talvez, como conseqüência disso, também ocorreu aumento da participação das publicações com autoria de discentes oriundos de programas de IES privadas no total de publicações com autoria discente dos programas do país.

Figura 3- Comparativo das participações das publicações discentes de IES privadas, participação dos programas das IES privadas e dos discentes matriculados em IES privadas.

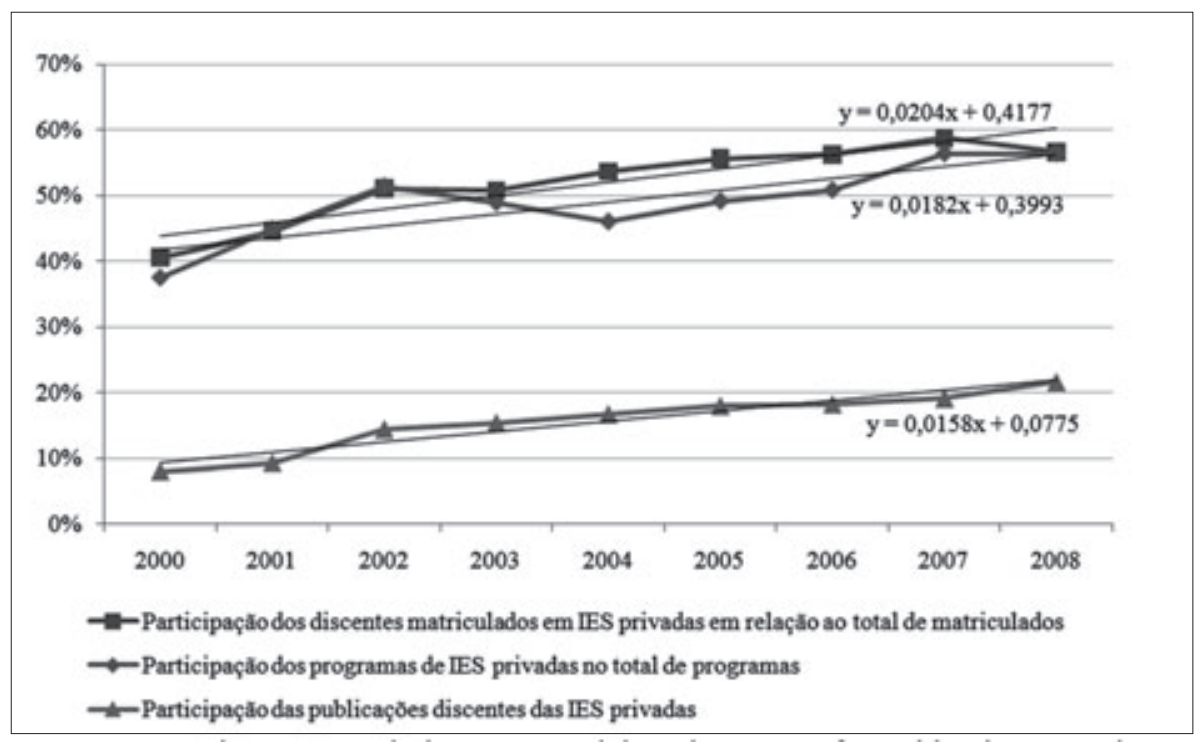

Fontes: as curvas de participação de discentes matriculados e de programas foram elaboradas a partir de GeoCapes (CAPES, 2010a); a curva de participação discente nas publicações em IES privadas foi elaborada pelos autores. 
Pode-se, ainda, introduzir uma diferenciação entre os tipos de estudantes predominantes entre IES de diferentes status jurídicos. Existem diferenças nas proporções de estudantes de mestrado acadêmico e estudantes de doutorado. Em 2000, nas IES públicas, os estudantes de mestrado correspondiam a 89\% e os de doutorado a 11\%. Em 2008, os estudantes de mestrado passaram ser $70 \%$ e, os de doutorado, 30\%. Ou seja, houve um aumento na proporção de estudantes de doutorado nas IES públicas no período. Por outro lado, nas IES privadas, os estudantes de mestrado representavam 82\% em 2000, passando a 83\% em 2008. Praticamente não houve alteração nas proporções de mestrandos e doutorandos nas IES privadas. Sabe-se que os estudantes de doutorado publicam, em média, mais do que os estudantes de mestrado (VELLOSO; VELHO, 2001). Assim, mesmo havendo mais estudantes de mestrado do que de doutorado compondo o corpo discente dos programas de IES privadas, seu maior quantitativo parece compensar sua menor produtividade.

Nessas comparações, o segmento público foi tomado de modo a agregar os programas municipais, estaduais e federais. Mas as participações podem ser conferidas para cada um desses segmentos separadamente. As participações médias no período para cada um são, respectivamente, 32\%, 69\% e $57 \%$. Pode-se afirmar que a participação discente nos programas das IES municipais é menor do que nos programas das IES estaduais $(\mathrm{p}<0,001)$ e federais ( $\mathrm{p}<0,001)$. A participação nos programas estaduais, por sua vez, é maior do que nos programas de IES federais ( $<<0,001)$. Dado que a média entre os três é 59\% (a média dos programas públicos), pode-se imaginar que os programas municipais atuam no sentido de reduzir a média, enquanto que os programas estaduais atuam no sentido contrário, aumentando a média.

Quando os programas são considerados de forma agregada, variáveis de caráter mais estrutural, como quantidades de matriculados, docentes e programas, parecem oscilar no mesmo compasso das quantidades de publicações e, também, da participação discente nas publicações. Tais variáveis possuem alguma capacidade determinante para a participação discente em pesquisas. $\mathrm{O}$ comportamento da quantidade de publicações com autoria discente ao longo dos anos, sem fazer distinção entre público ou privado, é, em grande parte, explicado pela quantidade de discentes matriculados $\left(\mathrm{R}^{2}=0,98\right)$. Apesar de a série temporal ser relativamente curta, outras variáveis, tomadas individualmente, também parecem ter poder explicativo elevado: as variações nas quantidades de programas $\left(\mathrm{R}^{2}=0,98\right)$, de docentes $\left(\mathrm{R}^{2}=0,97\right)$ e de titulados $\left(\mathrm{R}^{2}=0,90\right)$. A variação na quantidade de publicações com autoria discente 
possui relação com a variação da quantidade de docentes provavelmente devido à grande quantidade de co-autorias entre discentes e docentes.

É interessante notar que, diferentemente do que se confere no cenário da pós-graduação nacional, na área de Administração ocorreu um crescimento maior na quantidade de docentes do que de discentes matriculados no período considerado. Conforme dados da Capes (2010a), a quantidade de docentes na área de Administração passou de 539, em 2000, para 1.328, em 2008 (aumento de 146\%). Por outro lado, a quantidade de discentes matriculados passou de 2.686, em 2000, para 4.441, em 2008 (aumento de 65\%). O resultado disso é uma tendência decrescente da participação dos discentes no somatório entre discentes matriculados e docentes dos programas, que constituem os dois principais tipos de autores das publicações dos programas. Em 2000, a quantidade de discentes matriculados representava 83\% dessa soma. Em 2008, passou a representar 77\%. Porém, a participação discente em pesquisa, conforme conferido nas Figuras 1 e 2, é crescente ao longo do período. Desse modo, apesar de a participação discente estar diminuindo no somatório de discentes e docentes dos programas, sua participação relativa na quantidade de publicações vem aumentando.

Entretanto, cabe fazer uma ressalva sobre as relações especuladas nesta seção. Não se pode perder de vista que, em nível de programa, existem particularidades que podem diferenciá-los entre si quanto às participações discentes em pesquisa. Esta pode ser influenciada por diferentes políticas em cada caso: alguns programas podem demandar regimentalmente publicações discentes, outros podem exigir trabalhos finais de disciplina na forma de artigos mais do que outros, políticas de bolsas podem estimular uma maior participação discente nas atividades de pesquisa, pode-se estabelecer premiações, etc. Assim, a análise de casos individuais requer controle também dessas peculiaridades.

\subsection{Participação discente nas publicações por tipo de produto}

Poder-se-ia supor a existência de diferenças nas participações dos estudantes, nos três tipos de publicações (anais, periódicos e livros, esses últimos incluindo obras integrais, capítulos e organizações) entre os programas de IES privadas e de públicas. A Figura 4 compara essas participações ao longo do período. Nesse caso, o cruzamento das observações entre os segmentos público, privado e, ainda, entre anais, periódicos ou livros, tudo isso classificado entre os anos 2000 a 2008, levou a segmentos com quantidades muito pequenas de observações (em um caso foi igual a zero). Por isso, os nove anos do intervalo foram agrupados em apenas três pontos temporais. 
Figura 4- Comparação da participação discente na autoria de obras integrais, capítulos e organizações/coletâneas entre programas de IES públicas e privadas.

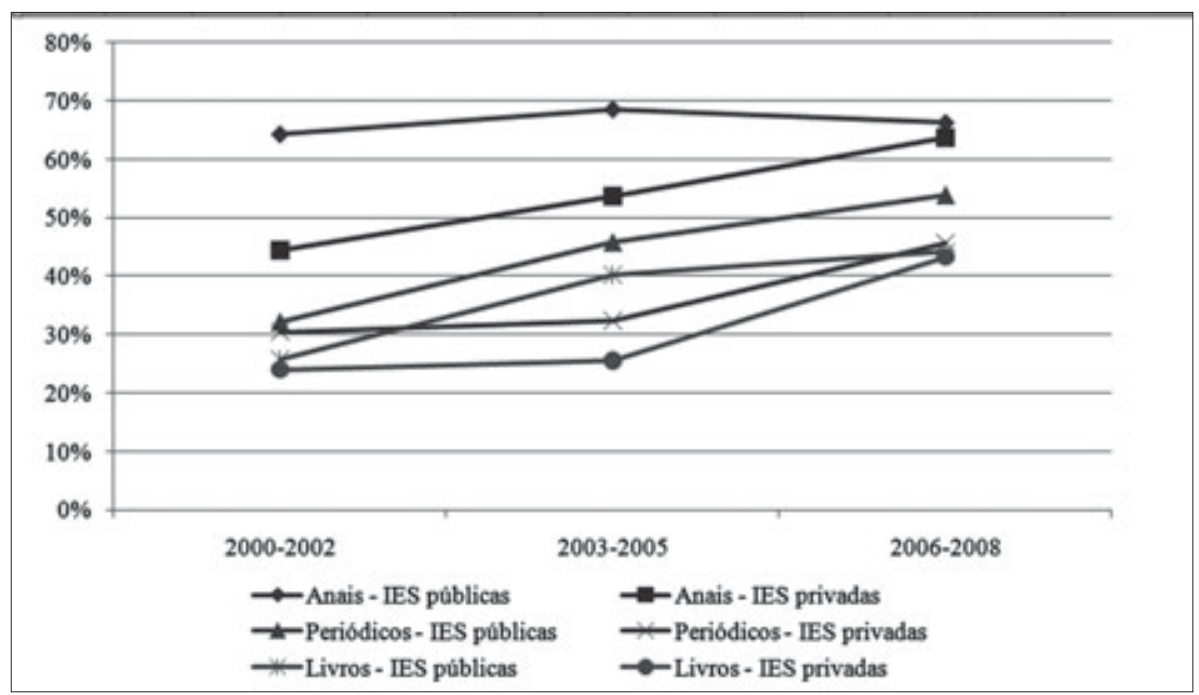

Fonte: elaborado pelos autores.

Tomando-se o período amostrado como um todo, as participações são sempre maiores nas IES públicas. No caso das publicações em anais, a participação média no período foi igual a $67 \%$ nas IES públicas e $57 \%$ nas privadas (p < 0,001). No entanto, a média "esconde" a tendência do período. No ponto 20002002, a participação nas IES públicas é significativamente maior do que nas privadas ( $\mathrm{p}<0,001$ ). Entretanto, no ponto 2006-2008, as participações podem ser consideradas não significativamente diferentes $(p=0,384)$.

Com relação às publicações em periódicos, apesar de a média da participação no período poder ser considerada maior nas IES públicas (48\%) do que nas privadas $(40 \%)(\mathrm{p}=0,034)$, as diferenças não são significativas nos três pontos quando tomados isoladamente (os p-valores dos intervalos 2000-2002, 2003-2005 e 2006-2008, são, respectivamente: 0,681; 0,052; e 0,123). Quanto às publicações em livros, não são significativamente diferentes nos três pontos (os p-valores dos intervalos 2000-2002, 2003-2005 e 2006-2008, são, respectivamente: 0,660; 0,061; e 0,794), tampouco na média do período ( $\mathrm{p}=0,298$ ).

Esses resultados podem ser interpretados como desdobramentos do que foi conferido nas Figuras 1 e 2. Há um crescimento da participação discente em programas de IES privadas em ritmo maior do que o aferido em programas 
de IES públicas, de modo que os percentuais são muito próximos nos últimos anos da série. No último período da Figura 4, não há diferenças significativas nas participações entre IES públicas e privadas em algum dos três tipos de publicações. Nesse meio, as publicações em anais são as que possuem maior freqüência em relação às demais, influenciando, em maior medida, a proximidade entre as participações nos diferentes tipos de IES. Assim, a Figura 4 pode ser vista como um desdobramento das Figuras 1 e 2, mas, agora, vista através dos tipos de publicação.

Cabe ressaltar que os perfis de publicações com autoria discente são muito semelhantes entre ambos os grupos de programas. Considerando-se o total de publicações com autoria discente de programas de IES públicas, 74,5\% ocorrem em anais de eventos, 16,3\% em periódicos e 9,1\% em livros. As publicações dos programas de IES privadas ocorrem em 75\% dos casos em anais, 15,9\% em periódicos e 9,1\% em livros (a comparação estatística resulta em p-valores para anais, periódicos e livros iguais a, respectivamente: 0,779; 0,749; e 0,912). Portanto, pode-se desconsiderar a possibilidade de influência do perfil de publicações nas participações discentes. Poder-se-ia supor, por exemplo, que os estudantes participam com maior freqüência nas publicações em anais de eventos e esta seria a forma de publicação mais comum entre programas de IES públicas, em relação às privadas, o que levaria a uma maior participação discente nesses programas. No entanto, não é esse o caso.

\section{CONCLUSÃO}

Essa pesquisa procurou identificar o grau de participação dos estudantes nas publicações dos programas de pós-graduação em Administração brasileiros. Deu-se ênfase à diferenciação entre IES públicas e privadas, a fim de se verificar possíveis diferenças nas respectivas participações. Para tanto, foi realizado um levantamento nas publicações de 38 programas da área de Administração, abrangendo o período entre 2000 e 2008.

Quando tomada de forma agregada, a participação discente parece ser bem explicada pela variação nas quantidades de programas, pelas quantidades de estudantes e pelas quantidades de docentes. Em princípio, essa relação é razoável, pois as publicações dos programas são elaboradas por professores e estudantes. Porém, nota-se algum crescimento na participação discente nas publicações de ambos os programas, públicos e privados, apesar de o aumento relativo na quantidade de docentes no período ter sido maior do que o conferido entre as quantidades de discentes matriculados ou titulados. 
Em geral, a participação discente média no período é maior nos programas de IES públicas do que nos programas de IES privadas. Entretanto, ocorre uma tendência de crescimento na participação discente relativamente acentuada entre os programas privados, de modo que a participação discente desses programas tende a se aproximar da participação discente nos programas de IES públicas. Quando se considera a participação em relação ao total publicado pelo SNPG de Administração, a participação das publicações com autoria discente provenientes de IES privadas é menor do que a participação das publicações com autoria de discentes provenientes de IES públicas. Mas, quando se considera a participação em relação ao total publicado em cada segmento (público e privado), as participações discentes tendem a se assemelhar, especialmente nos últimos anos da série histórica (2007 e 2008). O mesmo se observa quando se subdivide as publicações por tipo de produto. As participações podem ser diferentes nos primeiros anos da série, mas tendem a convergir nos últimos anos da série. Assim, pode-se observar que a participação discente, apesar de ter sido maior no âmbito público nos primeiros anos da série, em alguns casos, tende a ocorrer em níveis muito semelhantes entre o âmbito público e privado nos últimos anos do período, sendo que a participação nos programas de IES privadas apresenta maior crescimento tanto em relação ao total nacional quanto em relação ao total publicado apenas no âmbito privado.

Em suma, essas participações são reflexos da expansão do ensino superior privado no país conferido nas últimas décadas. Os programas de pós-graduação em Administração de IES privadas crescem em ritmo mais acelerado do que o verificado nas IES públicas, bem como em sua quantidade de estudantes. Esses fatores são diretamente relacionados aos níveis de publicações assinadas por discentes.

Este estudo pode ter sido, em parte, limitado por alguns efeitos inerentes às pesquisas que analisam autorias de publicações, como "autorias honorárias" ou "autores fantasmas". Trata-se de autores que efetivamente não contribuíram para o trabalho, mas constam como autores, podendo ter distorcido as proporções de publicações com autoria discente. Outra limitação diz respeito a deficiências dos dados contidos nos Cadernos de Produção Bibliográfica. Durante sua leitura, por exemplo, foram identificados alguns trabalhos publicados em anais classificados como resumo, em um caso, e texto completo, em outro, tendo sido ambos publicados no mesmo evento, no mesmo ano. 


\section{REFERÊNCIAS}

BAHRO, Horst; BECKER, Willi. Educação, pesquisa e desenvolvimento: o sistema de ensino, ciência e pesquisa na República da Alemanha. Brasília: Capes, 1979.

BRASIL. MINISTÉRIO DA EDUCAÇÃO E CULTURA. Conselho Nacional de Pós-Graduação. I Plano Nacional de Pós-Graduação (PNPG) 1975-1979. Brasília: Capes, 1975.

BRASIL. MINISTÉRIO DA EDUCAÇÃO E CULTURA. Coordenação de Aperfeiçoamento de Pessoal de Nível Superior. II Plano Nacional de PósGraduação (PNPG) 1982-1985. Brasília: Capes, 1982.

BRASIL. MINISTÉRIO DA EDUCAÇÃO. Coordenação de Aperfeiçoamento de Pessoal de Nível Superior. III Plano Nacional de PósGraduação (PNPG) 1986-1989. Brasília: Capes, 1986.

BRASIL. MINISTÉRIO DA EDUCAÇÃO. Coordenação de Aperfeiçoamento de Pessoal de Nível Superior. V Plano Nacional de PósGraduação (PNPG) 2005-2010. Brasília: Capes, 2004.

BRASIL. MINISTÉRIO DA CIÊNCIA E TECNOLOGIA. CoordenaçãoGeral de Indicadores - ASCAV/SEXEC. Brasil: Produção científica, segundo meio de divulgação no diretório dos grupos de pesquisa do Conselho Nacional de Desenvolvimento Científico e Tecnológico (CNPq), 2000-2008. 2009. Disponível em: <http://www.mct.gov.br/index.php/content/view/5703. html >. Acesso em: 19 abr. 2010.

CAPES. Coordenação de Aperfeiçoamento de Pessoal de Nível Superior. GeoCapes. 2010a. Disponível em: <http://geocapes.capes.gov.br/ geocapesds/>. Acesso em: 19 abr. 2010.

CAPES. Perguntas mais freqüentes. 2010b. Disponível em: < http://capes. gov.br/images/stories/download/coletadados/FAQ_Coleta_de_Dados_11. pdf $>$. Acesso em: 26 mai. 2010.

CLARK, Burton. The modern integration of research activities with teaching and learning. The Journal of Higher Education, Columbus, v. 68, n. 3, mai./jun., p. 241-255, 1997. 
COLLIS, Jill; HUSSEY, Roger. Pesquisa em Administração: um guia prático para alunos de graduação e pós-graduação. Porto Alegre: Bookman, 2005.

COOPER, Donald; SCHINDLER, Pamela. Métodos de pesquisa em Administração. Porto Alegre: Bookman, 2003.

DEMO, Pedro. Pesquisa: princípio científico e educativo. São Paulo: Cortez; Autores Associados, 1991.

DEMO, Pedro. Educar pela pesquisa. Campinas: Autores Associados, 1998.

DIAS SOBRINHO, José. Campo e caminhos da avaliação: a avaliação da educação superior no Brasil. In: FREITAS, Luiz Carlos de (org.). Avaliação: construindo o campo e a crítica. Florianópolis: Insular, 2002. p. 13-62.

FALLIS, George. The mission of the University. Postsecondary Review: Higher Expectations for Higher Education, Government of Ontario. 2004. Disponível em: <http://www.cou.on.ca/content/objects/The\%20Mission\%20 V3.pdf>. Acesso em: 27 nov. 2009.

GLÄNZEL, Wolfgang. Bibliometrics as a research field: a course on theory and application of bibliometric indicators. Courses Handouts, 2003. Disponível em: <http://www.norslis.net/2004/Bib_Module_KUL.pdf>. Acesso em: 26 maio 2010.

HOFFMANN, Rodolfo. Estatística para economistas. São Paulo: Pioneira, 1991.

HOSTINS, Regina Célia Linhares. OS Planos Nacionais de Pós-Graduação (PNPG) e suas repercussões na Pós-Graduação brasileira. Perspectiva, Florianópolis, v. 24, n. 1, p. 133-160, jan/jun. 2006.

KWIEK, Marek. Revisiting the classical German idea of the university (On the nationalization of the modern institution). Polish Journal of Philosophy, Krakón, v. 2, n. 1, p. 1-25, 2008.

MACCARI, Emerson Antonio; LIMA, Manolita Correia; RICCIO, Edson Luiz. Uso do sistema de avaliação por programas da área de Administração no Brasil. In: ENCONTRO DA ASSOCIAÇÃO NACIONAL DE 
PESQUISA E PÓS-GRADUAÇÃO EM ADMINISTRAÇÃO, 33., 2009, São Paulo. Anais... ANPAD: São Paulo, 2009. 1 CD-ROM.

MALHOTRA, Naresh. Pesquisa de marketing: uma orientação aplicada. Porto Alegre: Bookman, 2006.

MARTIN, Ben. The use of multiple indicators in the assessment of basic research. Scientometrics, Budapest, v. 36, n. 3, p. 343-362, 1996.

NOGUEIRA, Maíra Vasconcelos. Papel da pós-graduação no desenvolvimento de competências - um trabalho sob a óptica dos mestres em Administração. 2007. 107 f. Dissertação (Mestrado em Administração) - Programa de Pós-Graduação em Administração de Empresas, Pontifícia Universidade Católica de São Paulo, São Paulo, 2007.

NOLAN, Robert; ROCCO, Tonette. Teaching graduate students in the social sciences writing for publication. International Journal of Teaching and Learning in Higher Education, Blacksburg, v. 20, n. 2, p. 267-273, 2009.

OKUBO, Yoshiko. Bibliometric indicators and analysis of research systems: methods and examples. OECD Science, Technology and Industry

Working Papers, 1997/1. OECD Publishing, 1997. Disponível em: <http:// www.oecdilibrary.org/>. Acesso em: 26 maio 2010.

PARK, Chris. Redefining the doctorate. Discussion Paper. York: The Higher Education Academy, 2007. Disponível em: <http://www.grad.ac.uk/ downloads/documents/Reports/HEA/RedefiningTheDoctorate.pdf > . Acesso em: 18 abr. 2010.

PAULA, Maria de Fátima Costa de. USP e UFRJ: a influência das concepções alemã e francesa em suas fundações. Tempo Social, São Paulo, v. 14, n. 2, p. 147-161, 2002.

PAULA, Maria de Fátima Costa de. A formação universitária no Brasil: concepções e influências. Avaliação, Campinas; Sorocaba, v. 14, n. 1, p. 71-84, 2009.

ROBINS, Lisa; KANOWSKI, Peter. PhD by publication: a student's perspective. Journal of Research Practice, Athabasca, v. 4, n. 2, art. M3, 2008. 
RUEDA-CLAUSEN, Christian Federico; VILLA-ROEL, Cristina; RUEDACLAUSEN, Christian Eduardo. Indicadores bibliométricos: origen, aplicación, contradicción y nuevas propuestas. MedUNAB, Bucaramanga, v. 8, n. 1, p. 29-36, 2005.

SCHWARTZMAN, Simon. Um espaço para a ciência: a formação da comunidade científica no Brasil. Brasília: Ministério da Ciência e Tecnologia, Centro de Estudos Estratégicos, 2001.

SCHWARTZMAN, Simon; CASTRO, Cláudio de Moura. Apresentação. In: SCHWARTZMAN, Simon; CASTRO, Cláudio de Moura (Orgs.) Pesquisa universitária em questão. Campinas: Ed. UNICAMP; Ícone. São Paulo: CNPq, 1986. p. 9-10.

SGUISSARDI, Valdemar. Reforma Universitária no Brasil - 1995-2006: precária trajetória e incerto futuro. Educação \& Sociedade, Campinas, v. 27, n. 96 - Especial, p. 1021-1056, 2006.

TIMMONS, Stephen; PARK, Jennifer. A qualitative study of the factors influencing the submission for publication of research undertaken by students. Nurse Education Today, Edinburg, v. 28, p. 744-750, 2008.

VELLOSO, Jacques; VELHO, Léa. Mestrandos e doutorandos no país. Trajetórias de formação, Brasília: Capes; Unesco. 2001.

VERHINE, Robert Evan. Pós-Graduação no Brasil e nos Estados Unidos: uma análise comparativa. Educação, Porto Alegre, v. 31, n. 2, p. 166-172, maio/ago. 2008. 